\title{
PERMEATION BEHAVIOR OF WATER AND ACID SOLU- TION/VAPOR INTO UNDEGRADABLE POLYMER
}

\section{Dinh Van Chau ${ }^{1}$}

\begin{abstract}
Corrosion can be controlled by isolation of the metal from the corrosive environment.
\end{abstract} Isolation of corrodible metals from corrosive environments is probably the most general method of the corrosion protection afforded by paint films, sealers and lining on base materials. Fluoropolymers provide superior chemical resistance and are used in a variety of markets. These polymers are widely used to seal and isolate materials, especially under harsh conditions, in the chemical process industries and in the semi conductor, pharmaceutical, and biotechnology industries, where contamination may be critical. This study investigated the phenomenon of permeation only into the fluoropolymers materials lining under corrosive environment. Permeation behavior of water and acid solution or vapor into undegradable polymer is studied and explained. The weight changes generally increase with the increase of temperatures. Relatively rapid diffusion rate of water in the fluoropolymers sheets were observed from these results. Ethylene tetrafluoroethylene (ETFE) sheet absorbed less water but has the biggest diffusion coefficient than other fluoropolymers in this research. The highest weight uptake is obtained for PFA sheet immersion. The transport of water vapor is considered the same as water solution. In other words, they might move in the same phase. Weight changes could be plotted against square root time following Fickian diffusion type. Activation energy of water diffusion in fluoropolymer in liquid phase is higher than in vapor phase. The weight of fluoropolymers sheets could be recovered to the initial weight after dried at $50^{\circ} \mathrm{C}$ for four days.

Keywords: Polymer lining, permeation, anticorrosion.

Received: December 11, 2019 Accepted: December 12, 2019 Published on: December 20, 2019

\section{Introduction}

Isolation of corrodible metals from corrosive environments is the most general method of the anticorrosion afforded by paint film, sealers and lining on base materials. The material for lining is defined as physical materials used to protected or covered an inside surface. Lining are barrier applications used to protect base materials such as carbon steel, concrete, or other substrates from corrosive environment. Effective isolation requires that polymeric materials have good barrier properties and remain adherent in the presence of water, chemicals, gas, vapor and the products of metallic corrosion. Generally, lining has a low coefficient of friction and provide an easily cleanable surface. Economics play a part in determining whether it is more advantageous to line a base material or to select an appropriate corrosion resistant alloy as the base metal for construction. When high temperatures and high concentrations of chemicals rule out a lining system, or when downtime for repairing of a lining is unacceptable, the high alloy is frequently selected [1-5].

Although many corrosion-resistant metals and alloys are available, they do not always represent the most practical or economical means to prevent corrosion. In many situations it is better to selected a less resistant metal and provide some types of lining to protect it from corrosion. Lining may be made of plastic sheet, glass, or cement, or can be applied in liquid form [6-8].

${ }^{1}$ University of Engineering and Technology, Vietnam National University at Hanoi

Email: chaudv@moit.gov.vn 
Polymeric lining performs two important functions in metal equipment. First, it protects the equipment from deterioration by the corrosive and erosive action of chemicals and, second, it protects the quality of the product. The use of polymeric lining is the most common and economical means to protect base materials against corrosion. In general, good corrosion protection requires the establishment of good lining adhesion. To exhibit high performance ability for lining, adhesion must be maintained under the presence of water, electrolyte, and various products of the corrosion reactions [9-10]

For many years vessels or equipments have been successfully lined with various type of coating or lining material. Many vessels have given over 20 years of reliable service. However, there are occasionally reports of lining failures that can be traced. Inadequate surface preparation, thermal stresses, permeation, debonding and operation condition are found to be the main problems in lining failure, especially permeation of solution and vapor. In order that lining should offer protection from corrosion, it should withstand to one or other of the processes of blistering/delamination and corrosion reactions. This was considered by Mayne [11], who determined that the permeability of organic coatings to both water and oxygen is so high that the rate at which they arrive at the interface of the coating and steel is greater than that required for corrosion to proceed. Water at the organic coating/substrate interface is often the main cause of degradation of organic coating systems. Kamal and Saxon [12] claimed that water has at least three kinds of effects in the degradation of polymers. One is chemical effect: hydrolysis of the ester or amide bonds. The second is physical effect: loss of the bond between the coating and substrate. The third is photochemical effect: generation of hydroxyl radicals or other chemical species which may react with polymers.

Chemicals other than water can also permeate in and degrade a lining which it affects performance. Moreover, this chemical also can accumu- late on the bond interface of lining-metal system. The combination of permeation and lining degradation will reduce the life time of lining as a consequence of increasing of permeation rate of chemicals and corrosion rate of substrate.

Many lining failures are caused by the permeation of environmental solution or vapor that result to the blisters and lining delamination. In some cases, environment solution or gas/vapor reacts with polymer lining or base materials to form corrosion product and make the lining to be failure. The failure of lining will cause the destruction of base materials and leakage which may represent a serious hazard to personnel [13]. In addition, the failure of lining part or the destruction of base materials will contaminate the product.

Permeation is defined as the process by which a chemical move through a material on a molecular level [14]. The three steps process includes:

- Absorption: Chemical is absorbed into the outer surface of a material.

- Diffusion: Chemical then diffuses through the material on a molecular level.

- Desorption: Chemical emerges on the inside surface of the material.

On other hand, penetration is defined as the physical transport of a chemical from one side of the material to the other side of the material, such as through imperfections, holes, tears, etc [15]. All materials are somewhat permeable to chemical molecules, but plastic materials tend to be an order of magnitude greater in their permeability rate. Gases, vapor, or liquids will permeate polymers. Factors effecting permeation are concentration of the solute, temperature of the media, time of exposure and liner thickness.

Thermoplastic fluoropolymers play a key role in materials integrity management by protecting the high purity materials during transport, processing and storage. Fluoropolymers provide superior chemical resistance and used in a variety of markets. These polymers are widely used to seal and isolate materials, especially under harsh conditions, in the chemical process industries 


\section{RESEARCH ARTICLE}

and in the semi conductor, pharmaceutical, and biotechnology industries, where contamination may be critical.

Fluoropolymers are often chosen for corrosive services due to their relative cost position compared with high alloy materials and due to their availability. Fluoropolymers products afford excellent chemical resistance towards aggressive solution. However, one of the downfalls of these materials is that certain chemicals in liquid and gas phase can permeate and reach the base metal components causing product failure.

Permeation is an important factor in determining the suitability of a particular polymer for specific applications such as protective coatings, packaging materials, selective separations, biomedical devices, etc. Understanding the mechanisms of permeation can help in the selection of materials, as well as in product or process development. Permeation is affected by several factors such as concentration of the solution, temperature of solution and time of exposure. In this work, the effects of these factors on permeation characteristic of corrosive environment are discussed.

\section{Experimentals}

The evaluation of fluoropolymers sheets and lining performance under corrosive environment were performed by measuring the diffusion performance, permeation depth of permeant element, observing the blisters formation and lining delamination.

\subsection{Materials and conditions}

The evaluation of fluoropolymers sheets under corrosive environment were performed by measuring the diffusion performance and permeation depth of acid element. The fluoropolymers utilized in the present study are ETFE (poly(ethylenecotrifluoroethylene)), PFA (poly(tetrafluoroethylene-co-perfluoroalkylvinyl ether)) and FEP (poly(tetrafluoroethylene-cohexafluoro propylene)) sheets ( $65 \times 25 \times 1.4 \mathrm{~mm}$ in size) as test material. These fluoropolymers are commonly used as lining material. The structures of chain of these fluoropolymers are shown in Fig. 1.

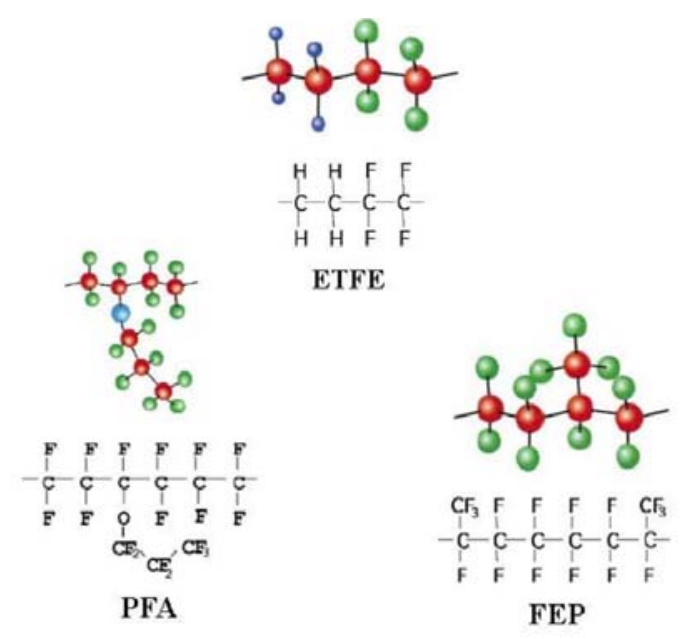

Fig. 1. Chemical structure of ETFE, FEP and PFA

Table 1 shows the properties of these fluoropolymers. Before permeation test, specimens were dried in drying oven at $50^{\circ} \mathrm{C}$ for at least 100 hours. Permeation test in liquid and vapor phase were done for sheets at different temperatures and concentrations. Fluoropolymer sheets test were examined with simple immersion test in order to measure the diffusivity and characteristic of fluoropolymers.

Table 1. Engineering thermoplastic fluoropolymers generally used for lining

\begin{tabular}{lccc}
\hline Fluoropolymer & Abbreviation & $\begin{array}{c}\boldsymbol{T}_{\boldsymbol{m}} \\
\boldsymbol{\rho} \boldsymbol{C})\end{array}$ & $\boldsymbol{E}(\boldsymbol{G P a})$ \\
\hline $\begin{array}{l}\text { Poly(ethylene- } \\
\text { co- } \\
\text { trifluoroethylen }\end{array}$ & ETFE & $\begin{array}{c}225- \\
270\end{array}$ & 1.0 \\
$\begin{array}{l}\text { e) } \\
\begin{array}{l}\text { Poly(tetrafluoro } \\
\text { ethylene-co- }\end{array}\end{array}$ & & & \\
$\begin{array}{l}\text { perfluoroalkylvi } \\
\text { nyl } \\
\text { ether) }\end{array}$ & PFA & $285-$ & $0.5-0.6$ \\
$\begin{array}{l}\text { Poly(tetrafluoro } \\
\text { ethylene- } \\
\text { cohexafluoro }\end{array}$ & & 310 & \\
propylene) & FEP & $250-$ & $0.4-0.5$ \\
\hline
\end{tabular}

\subsection{Permeation test}

Fluoropolymers sheets were immersed in water and hydrochloric acids solution as shown in Fig. 2a. The specimens were arranged with Teflon tube and immersed it in solution for simple immersion test. These tests were done at $40^{\circ} \mathrm{C}, 60^{\circ} \mathrm{C}$ and $80^{\circ} \mathrm{C}$. One side permeation test was kept by the instrument shown in Fig. 2b. In 
this test, both of vapor and liquid phase were done at the same time. Glass cell was filled with $\mathrm{HCl}$ solution to hall of glass cell volume. This setting provides half of volume as a vapor phase and liquid phase for liquid phase. The specimens were contacted with acid vapor and liquid at one side and air at opposite side. Temperatures of both sides were kept constant at specific temperatures.

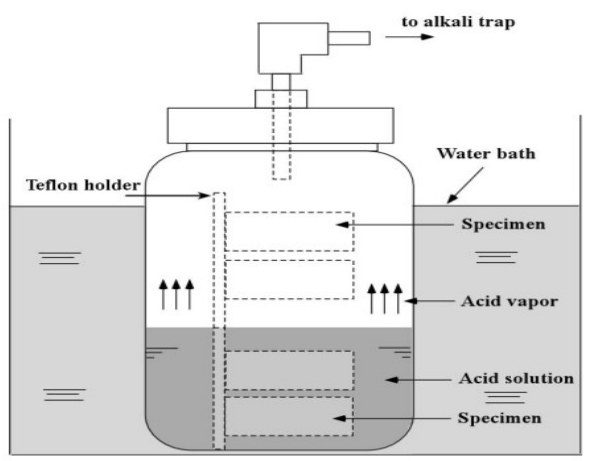

(a)

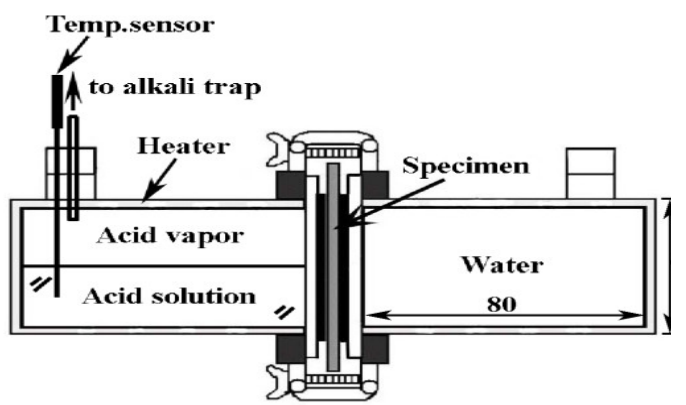

(b)

Fig. 2. Schematic apparatus of simple immersion test on fluoropolymer film in liquid and vapor phase (a) simple immersion test (b) one side immersion in glass cell

\subsection{Permeation analysis}

\subsubsection{Measurement of weight change}

Permeant diffusion in polymers may be determined by measuring the weight change for investigating the solubility and diffusion of solution in polymers. Specimens were removed at regular time and weighed using microbalance. The penetrant uptake was determined by obtaining the change in mass of specimen at different times, relatives to the initial mass. From this weight change, the characteristic of $\mathrm{HCl}$ solution transport in liq- uid and vapor phase can be observed.

\subsubsection{Energy Dispersive X-Ray Spectrometer} (EDS)

An Energy Dispersive X-Ray Spectrometer (EDS) analyzes elements by irradiating samples with electron beam, and detecting and analyzing $\mathrm{X}$-rays (characteristic X-rays) generated on the samples. EDS measures the energy and intensity distribution of X-ray signals generated by the electron beam striking the surface of the specimen. The elemental composition at a point, along a line, or in a defined area can be easily determined. Fig. 3 shows the EDS analysis system schematically.

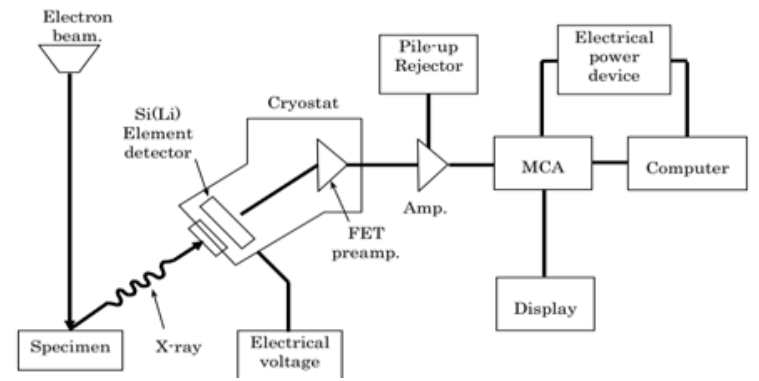

Fig. 3. Schematic of EDS analysis system

Penetration depths of chlorine $(\mathrm{Cl})$ element in this research were monitored by combination of scanning electron microscope (SEM) and X-ray analysis on cross section of polymer. JSM5310LV (for SEM) and JED 2100 (for EDS) were used for this analysis. Acceleration voltage was set to be $25 \mathrm{kV}$, LC (Load current) 60 90 $\mu \mathrm{A}$, WD (Work distance) 19 20 mm, and SS (spot size) 16 18. EDS results described the distribution of chlorine element in polymer, and penetration depths was determined from this profile.

\section{Results and Discussion}

\subsection{Permeation behavior of water and acid solution/vapor into undegradable polymer}

3.1.1. Permeation characteristic of water and water vapor at different temperatures

Figs. $4 \mathrm{a}-4 \mathrm{c}$ shows the weight change of fluoropolymers ETFE, PFA and FEP respectively, after immersed into water at different temperatures condition. The weight changes generally increase with the increase of temperatures. Rel- 


\section{RESEARCH ARTICLE}

atively rapid diffusion rate of water in the fluoropolymers sheets compared with general polymers were observed from these results. Saturation stage was generally obtained less than 4 days. In some cases, the saturation stage is achieved at 24 hours period of permeation test (ETFE, at $90^{\circ} \mathrm{C}$ ). ETFE sheet absorbed less water than other fluoropolymers in this research. The highest weight uptake is obtained for PFA sheet immersion. In addition, in all polymers, even high weight uptake is found in liquid phase at high temperature $\left(90^{\circ} \mathrm{C}\right)$, generally there is no significant difference between weight change of fluoropolymers in vapor and liquid phase of water. The transport of water vapor is considered the same as water solution. In other words, they might move in the same phase.

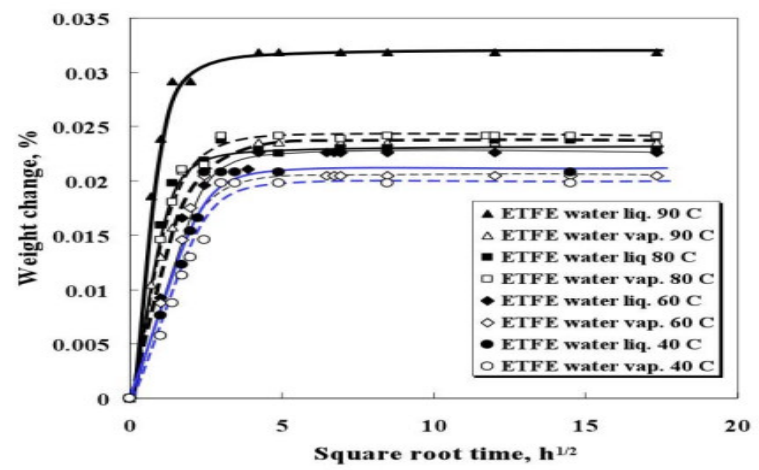

(a)

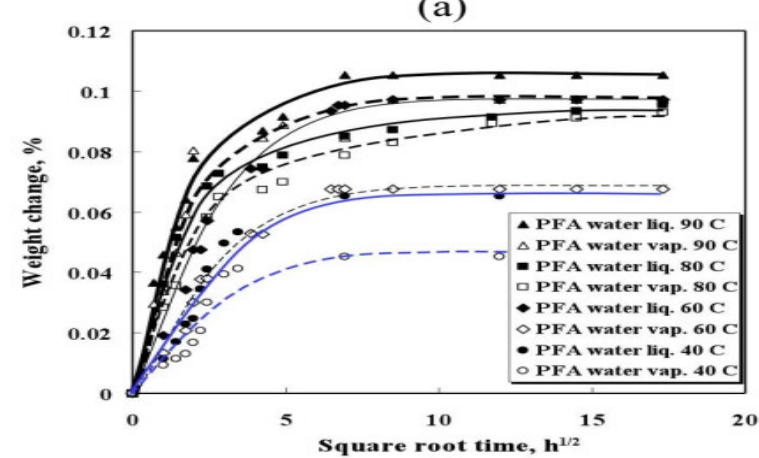

(b)

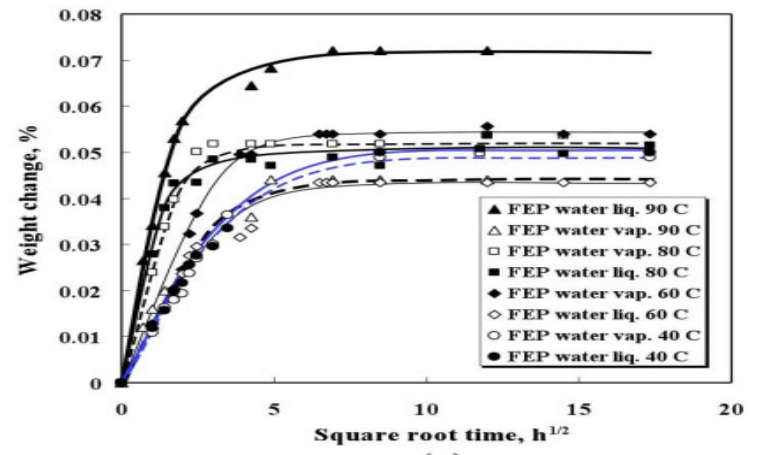

(c)

Fig. 4. Weight change of fluoropolymers after immersed into water at liquid and vapor phase at different temperatures (a) ETFE (b) PFA (c) FEP
Table 2. Diffusion coefficients of water in fluoropolymers at different temperatures

\begin{tabular}{ccccccccc}
\hline Fluoropolymer & \multicolumn{4}{c}{ Diffusion coefficient, $\mathrm{cm}^{2} / \mathrm{s}\left(10^{-8}\right)$} \\
\cline { 2 - 9 } & \multicolumn{4}{c}{$\begin{array}{c}\text { Liquid phase, temperature } \\
\left({ }^{\circ} \mathrm{C}\right)\end{array}$} & \multicolumn{5}{c}{ Vapor phase, temperature } \\
& \multicolumn{4}{c}{$\left.{ }^{\circ} \mathrm{C}\right)$} & \\
\cline { 2 - 9 } & 40 & 60 & 80 & 90 & 40 & 60 & 80 & 90 \\
\hline ETFE & 13.7 & 20.7 & 35.8 & 52.7 & 11.1 & 18.5 & 29.9 & 29.6 \\
\hline PFA & 13.7 & 1.76 & 2.88 & 2.97 & 1.15 & 1.47 & 1.89 & 2.67 \\
\hline FEP & 13.7 & 2.6 & 8.29 & 8.05 & 1.65 & 2.03 & 6.64 & 5.76 \\
\hline
\end{tabular}

Weight changes could be plotted against square root time following Fickian diffusion type [8]. Diffusion coefficient was determined from simple relation of Fickian diffusion.

Table 3 shows the diffusion coefficients of water in fluoropolymers at different temperatures. ETFE has the highest diffusion coefficient compare with other fluoropolymers. On the other hand, it has the lowest weight uptake, which it might be caused of low free volume. PFA has small diffusion rates but high weight uptake among the others. It means that PFA could absorb more water in long period of permeation time.

The relationship between diffusion coefficients of fluoropolymers and temperatures is shown in Fig. 5 and the activation energy for each temperature and fluoropolymers are presented in Table 3.

Table 3. Activation energy of fluoropolymers immersed in water

\begin{tabular}{ccc}
\hline \multirow{2}{*}{ Fluoropolymer } & \multicolumn{2}{c}{ Activation energy } \\
\cline { 2 - 3 } & Liquid phase & Vapor phase \\
\cline { 2 - 3 } & $\mathrm{E} / \mathrm{kJ} / \mathrm{mol}$ & $\mathrm{E}, \mathrm{kJ} / \mathrm{mol}$ \\
\hline ETFE & 24.95 & 19.80 \\
\hline PFA & 15.77 & 14.83 \\
\hline FEP & 32.21 & 28.00 \\
\hline
\end{tabular}

Activation energy of water diffusion in fluoropolymer in liquid phase is higher than in vapor phase. Moreover, PFA has the lowest activation energy compared with others (ETFE and FEP). FEP is found to have the highest one. In lining application, PFA is better to be used as lining material due to low diffusion rate of water. The performance of FEP is found between ETFE and PFA.

The weight of fluoropolymers sheets could be recovered to the initial weight after dried at $50^{\circ} \mathrm{C}$ for 4 days. 


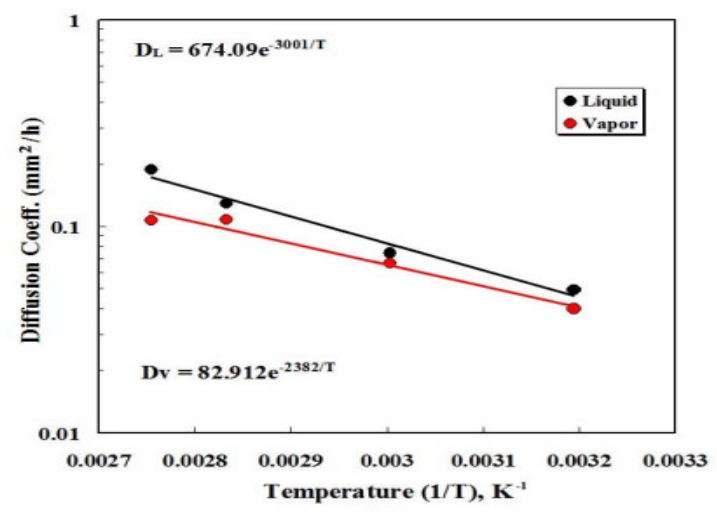

(a)

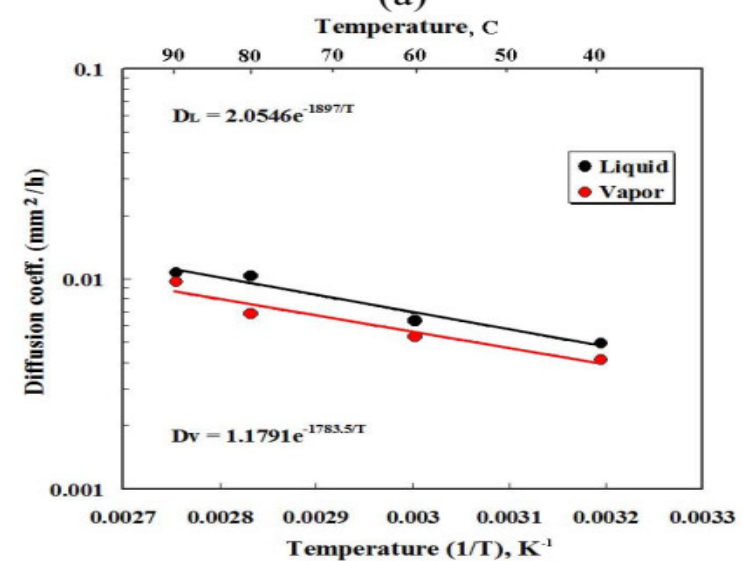

(b)

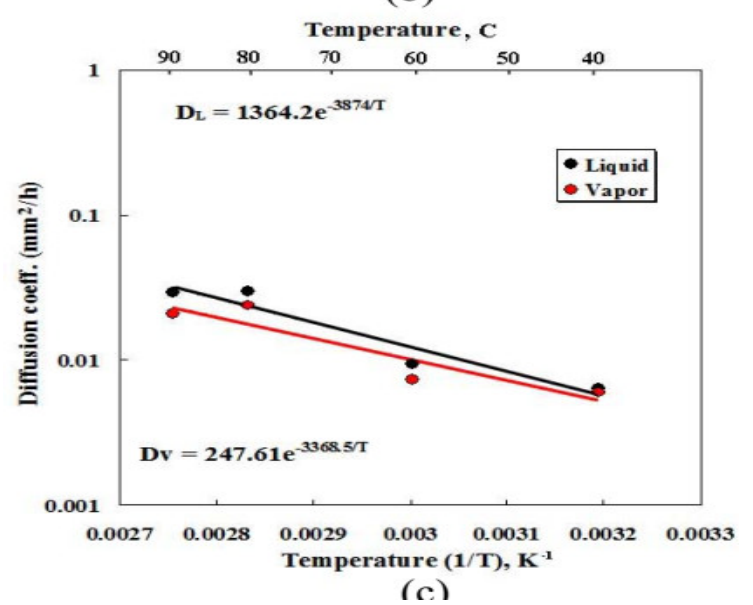

Fig. 5. Relation between diffusion coefficient of water in fluoropolymers and temperature after immersion test (a) ETFE (b) PFA (c) FEP

\subsubsection{Permeation of acid solution/vapor at} different temperatures

The weight change of the fluoropolymers ETFE, PFA and FEP immersed in 35 mass $\% \mathrm{HCl}$ in both solution and vapor phase are illustrated in Figs. $6 \mathrm{a}-6 \mathrm{c}$ as function of time at different temperature. It is observed that saturation is quickly reached within few hours for ETFE at the three temperatures as compared to PFA and FEP, nevertheless the saturation is also quickly reached for these later polymers. The highest weight gain is obtained in order for PFA $>$ FEP $>$ ETFE. As for the case of water immersion, the change in weight gain is found to be almost similar for both solution and vapor phase, only PFA reveals a small difference between the weight change for acid solution and for acid vapor. Even though, ETFE shows the lowest saturation value it has the highest diffusion coefficient as calculated by the same method already described in the case of water immersion.

Table 4 highlights the diffusion coefficient of acid in fluoropolymers at different temperatures, it is observed an alike behavior for the three polymer that is a drastic decrease in the diffusion coefficient as temperature decrease; the highest values of the diffusion coefficient are obtained for liquid solution as compared to vapor phase.

Table 4. Diffusion coefficients of 35 mass\% $\mathrm{HCl}$ in fluoropolymers at different temperatures

\begin{tabular}{ccccccc}
\hline Fluoropolymer & \multicolumn{3}{c}{ Diffusion coefficient, $\mathrm{cm}^{2} / \mathrm{s}\left(10^{-8}\right)$} \\
\cline { 2 - 7 } & \multicolumn{3}{c}{$\begin{array}{c}\text { Liquid phase, temperature } \\
\left({ }^{\circ} \mathrm{C}\right)\end{array}$} & $\begin{array}{c}\text { Vapor phase, } \\
\text { temperature } \\
\left({ }^{\circ} \mathrm{C}\right)\end{array}$ \\
\cline { 2 - 7 } & 40 & 60 & 80 & 40 & 60 & 80 \\
\hline ETFE & 8.04 & 11.00 & 19.98 & 7.31 & 9.73 & 14.85 \\
\hline PFA & 3.54 & 4.66 & 7.61 & 3.01 & 4.67 & 6.55 \\
\hline FEP & 3.03 & 3.74 & 7.50 & 2.40 & 3.28 & 6.69 \\
\hline
\end{tabular}

Alike water immersion, similar results are obtained for acid immersion, ETFE has the highest diffusion coefficient compare to the other polymer, this might be due to low free volume as previously explained. In spite of this, FEP has the lowest value although close to those of PFA.

As compared to the result of water immersion, the weight change for ETFE in acid is within the same level, with higher diffusion coefficient for water compare to that of acid, this means that ETFE is less responsive to the environment as compared to PFA and FEP where the weight gain is much higher in the case of acid as compared to that of water, with a higher diffusion coefficient. This confirms the previous suggestion that PFA is better as lining material as compared to ETFE. 


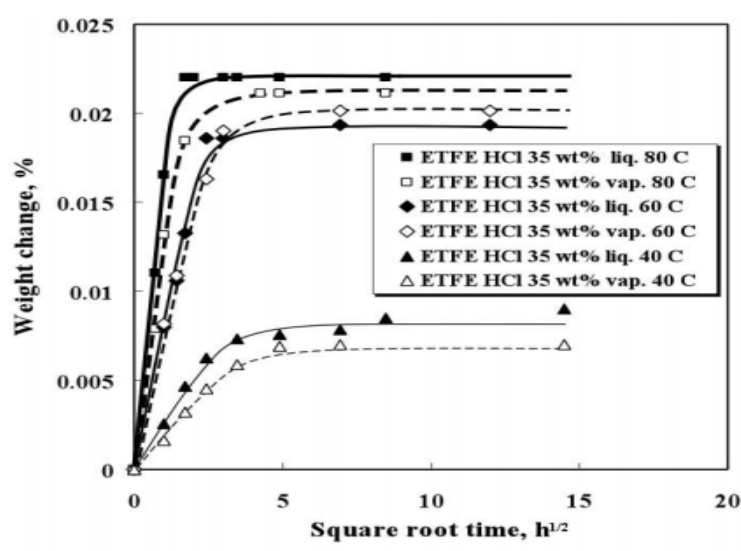

(a)

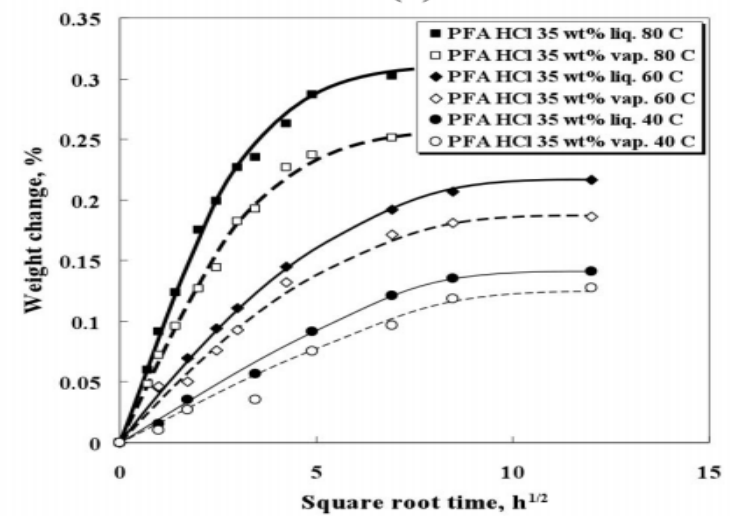

(b)

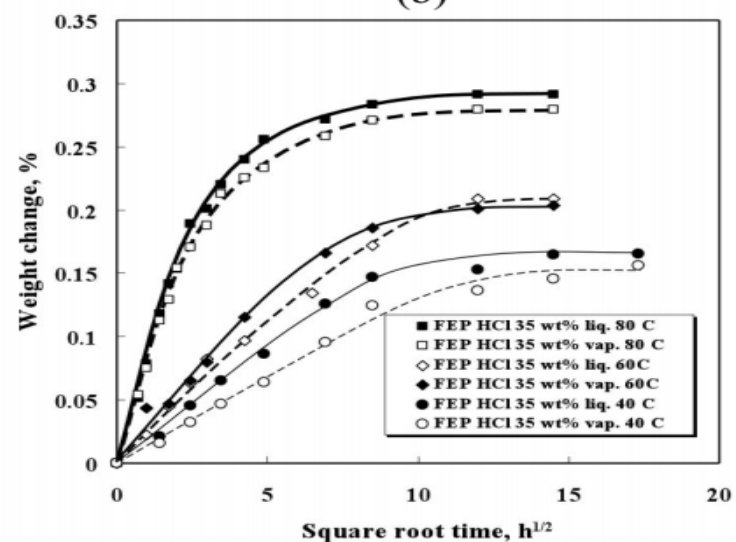

(c)

Fig. 6. Weight change of fluoropolymers after immersed into $\mathrm{HCl}$ solution at liquid and vapor phase at different temperatures (a) ETFE (b) PFA (c) FEP

Table 5. Activation energy of fluoropolymers immersed in acid

\begin{tabular}{ccc}
\hline \multirow{2}{*}{ Fluoropolymer } & \multicolumn{2}{c}{ Activation energy } \\
\cline { 2 - 3 } & Liquid phase & Vapor phase \\
\cline { 2 - 3 } & $\mathrm{E} / \mathrm{kJ} / \mathrm{mol}$ & $\mathrm{E}, \mathrm{kJ} / \mathrm{mol}$ \\
\hline ETFE & 41.66 & 32.42 \\
\hline PFA & 34.84 & 35.81 \\
\hline FEP & 41.15 & 46.72 \\
\hline
\end{tabular}

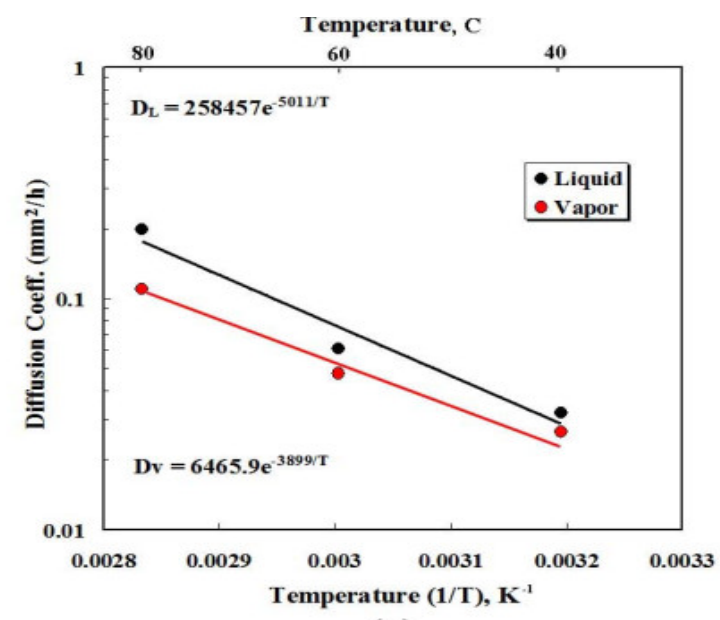

(a)

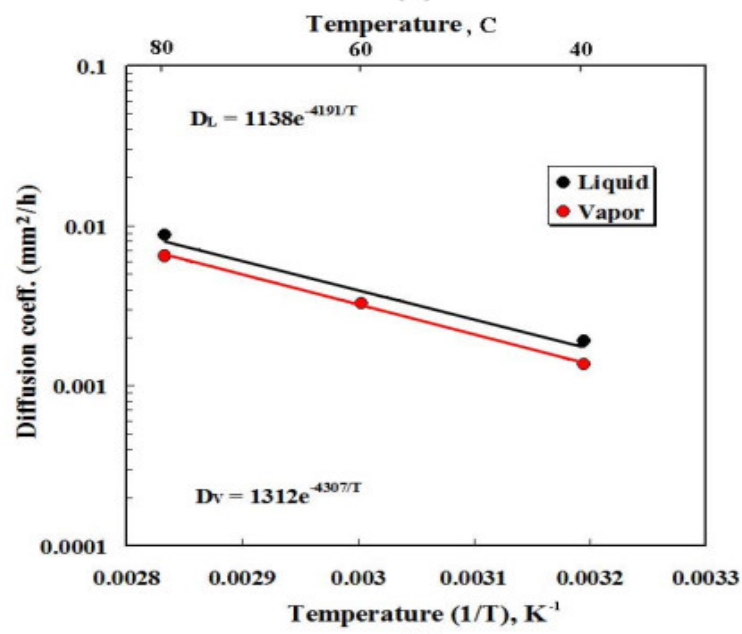

(b)

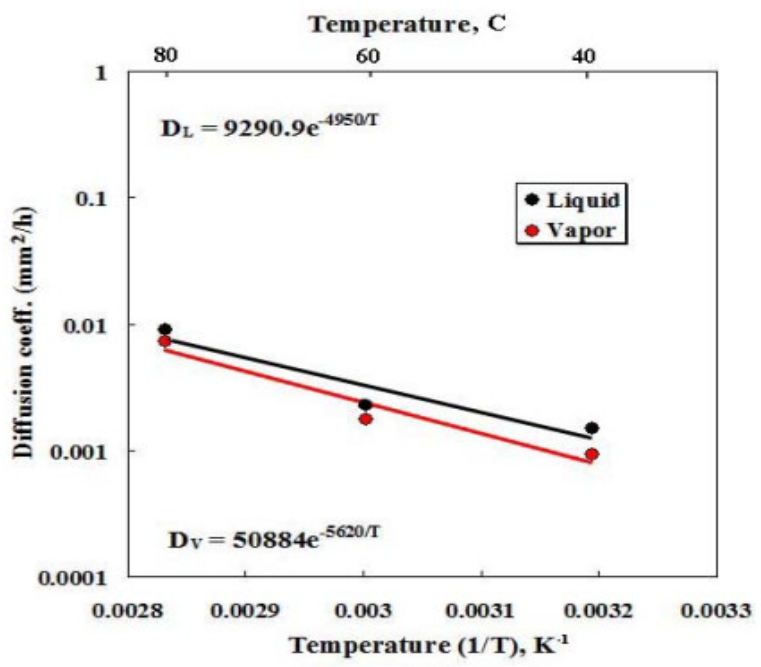

(c)

Fig. 7. Relation between diffusion coefficient of water in fluoropolymers and temperature after immersion test (a) ETFE (b) PFA (c) FEP 
The activation energy is derived from the relation between diffusion coefficient and the temperature of immersion, illustrated in Fig. 7 for respectively ETFE, PFA and FEP. It is observed for the three polymers lower value for vapor phase than liquid one, with practically parallel curves. The values of the activation energy are reported in Table 5; higher activation energy in the case of liquid than those of vapor phase for the three polymers are obtained roughly. PFA shows the lowest one as in the case of water immersion.

The weight of fluoropolymers sheets immersed in acid could not be recovered to the initial weight after dried at $50^{\circ} \mathrm{C}$ even for 2 weeks. $\mathrm{HCl}$ is considered remain inside the polymer.

\subsection{SEM / EDS analysis of the permeation} of acid solution/vapor at different temperatures

EDS analysis performed for polymers immersed in $\mathrm{HCl}$ revealed the presence of the $\mathrm{Cl}$ element inside the polymer, a typical illustration as shown in Fig. 8 for PFA immersed in 35 mass $\% \mathrm{HCl}$ at $80^{\circ} \mathrm{C}$, reveals the presence of the element $\mathrm{Cl}$, and this mean that acid was really diffused within the polymer sheet. Further analysis by SEM/EDS of the immersed specimens in both acid liquid and vapor phase, also confirmed the diffusion of $\mathrm{Cl}$ element within all the cross section of the sheets expressed as the red curve within the graphs as observed in Fig. 9 and Fig. 10 for ETFE, PFA and FEP after permeation in vapor and liquid respectively. It is observed a similar profile of diffusion for both environments and also a similar profile for the three polymers.

In contrast, no $\mathrm{Cl}$ element was observed for specimen immersed in 5 mass $\% \mathrm{HCl}$ solution for 24 hours as illustrated in Fig. 11 for the case of ETFE, this is also valid for the two other polymers. It has to be noted that the specimen at $24 \mathrm{hrs}$ was already saturated and that weight change leveled off; this denotes that diffusion is additionally affected by the concentration of acid.

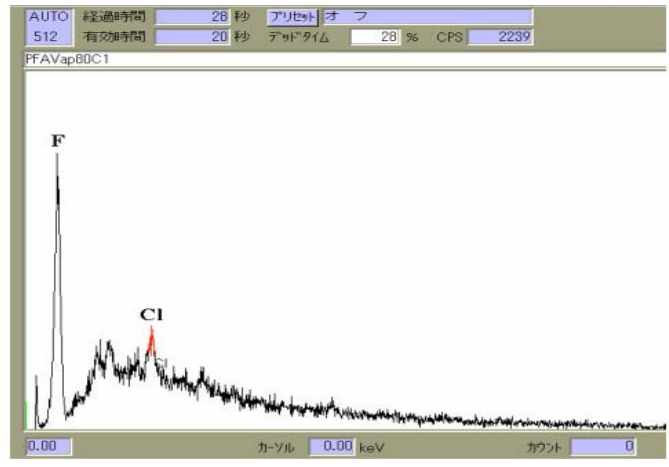

(a)

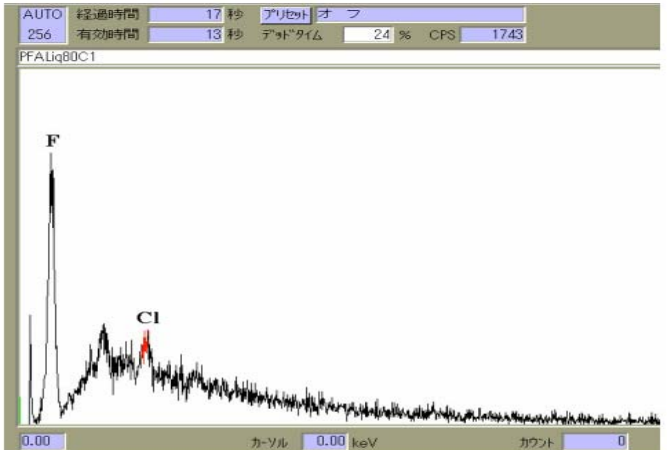

(b)

Fig. 8. Cl element intensity measurement on cross section of PFA after permeation test in 35 mass \% of $\mathrm{HCl}$ solution at $80^{\circ} \mathrm{C}$ (a) vapor phase condition (b) liquid phase condition
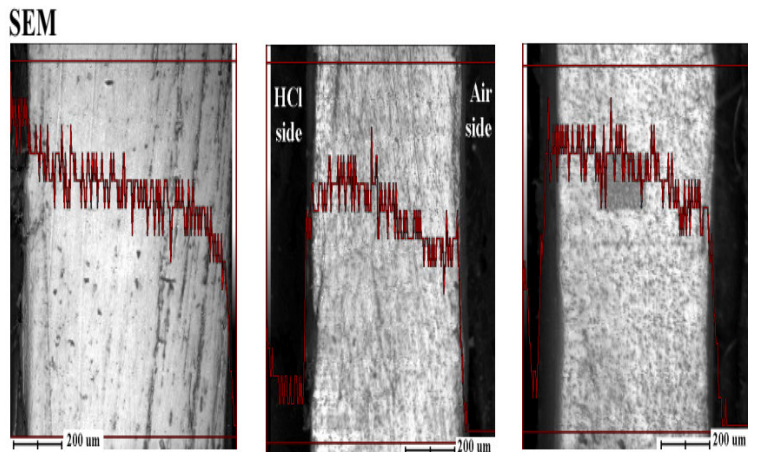

EDS
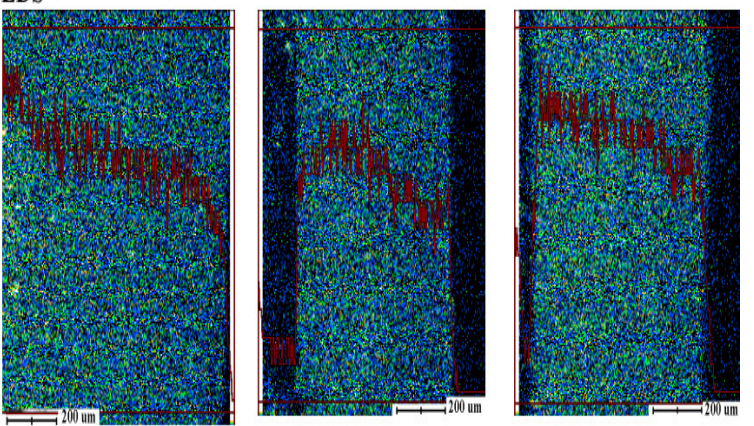

ETFE

PFA

FEP

Fig. 9. Clelement analysis on cross section of FTFE, PFA, FEP specimens after permeation test in liquid phase condition at $80^{\circ} \mathrm{C}(35$ mass $\% \mathrm{HCl}$ solution) $40^{\circ} \mathrm{C}$ (cooling water) temperature gradient for 6 hours 


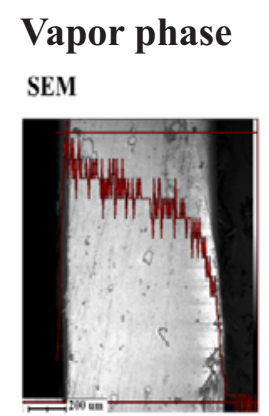

EDS

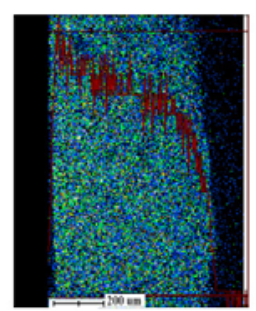

ETFE
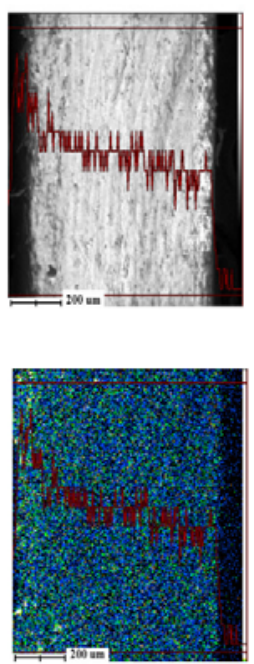

PFA
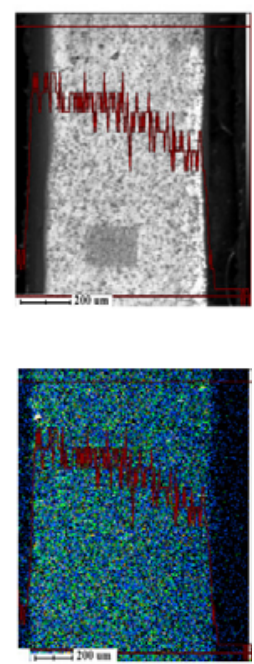

FEP

Fig. 10. Cl element analysis on cross section of ETFE, PFA, FEP specimens after permeation test in vapor phase condition at $80^{\circ} \mathrm{C}(35$ mass $\% \mathrm{HCl}$ solution) $-40^{\circ} \mathrm{C}$ (cooling water) temperature gradient for 24 hours

\section{Conclusions}

Permeation behavior of water and acid solution or vapor into undegradable polymer is studied and explained. The weight changes generally increase with the increase of temperatures. Relatively rapid diffusion rate of water in the fluoropolymers sheets were observed from these results. ETFE sheet absorbed less water than other fluoropolymers, however, it has the biggest diffusion. The highest weight uptake is obtained for PFA sheet immersion. Generally, there is no significant difference between weight change of fluoropolymers in vapor and liquid phase of water. The transport of water vapor is considered the same as water solution. In other words, they might move in the same phase. Weight changes could be plotted against square root time following Fickian diffusion type. Activation energy of water diffusion in fluoropolymer in liquid phase is higher than in vapor phase. The weight of fluoropolymers sheets could be recovered to
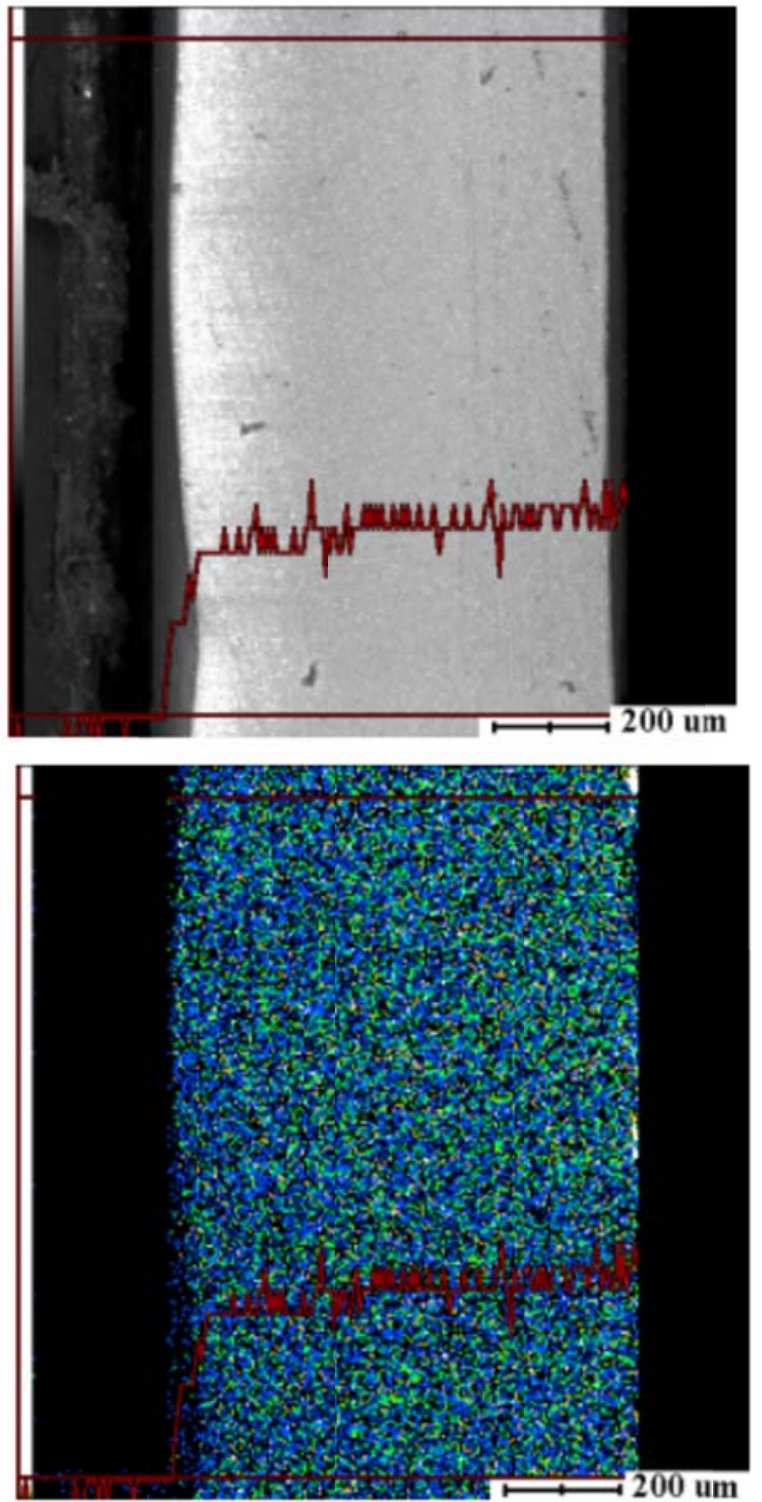

Fig. 11. Cl element analysis on cross section of ETFE specimens after immersion test in liquid phase condition at $80^{\circ} \mathrm{C}(5$ mass $\%$ $\mathrm{HCl}$ solution) for 24 hours

the initial weight after dried at $50 \mathrm{oC}$ for four days.

As for the case of water immersion, the change in weight gain immersed in 35 mass \% $\mathrm{HCl}$ solution is found to be almost similar for both solution and vapor phase. The diffusion coefficient of acid in fluoropolymers at different temperatures are observed an alike behavior for the three polymer that is a drastic decrease in the diffusion coefficient as temperature decrease. In 
term of activation energy, higher activation energy in the case of liquid than those of vapor phase for the three polymers are obtained. The weight of fluoropolymers sheets immersed in acid could not be recovered to the initial weight. Also, it is noted that PFA shows the lowest one, as in the case of water immersion, this makes PFA more valuable as lining material.

Acknowledgement: This work partial supported by the People's Committee of Ha Noi City under project "Nghiên cưu chế tạo hệ vật liệu epoxy biến tính và công nghệ phủ bảo vệ bằng epoxy biến tính có tính năng chống ăn mòn cao, gia cuờng, sư dụng làm ống thoát nước thải đô thị".

\section{References}

1. Dickie, R.A., (1986), Polymeric materials for corrosion control. American Chemical Society, Washington DC.

2. Dillon, C.P., (1986), Corrosion control in the chemical process industries. Mc Graw-Hill, New York.

3. Zolin, B.I., (1970), Protective Lining Performance. Chemical Engineering Progress, 66 (8), 3137.

4. Schweitzer, P.A., (2001), Corrosion-Resistant Linings and Coatings. Marcel Dekker Inc., New York.

5. Corti, H., Fernandez-Prini, R., (1982), Protective organic coatings: Membrane properties and performance Progress in Organic Coatings, 10, 5-33.

6. Nguyen, T., Hubbard, J.B., McFadden, G.B. (1991), A Mathematical Model for the Cathodic Blistering of Organic Coatings on Steel Immersed in Electrolytes. Journal of Coatings Technology, 63 (794), 43-51.

7. Pommersheim, J.M., Nguyen, T., Zhang, Z., Hubbard, J.B, (1994), Unified Model for the Degradation of Organic Coatings on Steel in a Neutral Electrolyte. Progress in Organic Coatings, $25,23-44$.

8. Hansen, C.H., (2001), Progress in Organic Coatings, 42, 167-178.

9. Leidheiser, J.R.H., (1982), Corrosion of Painted Metals-A Review, Corrosion-Nace, 38 (7), 374-383.

10. Nguyen, T., Bentz, D., Byrd, E., (1994), A study of water at the organic coating/substrate interface. Journal of coatings technology, 66 (834), 39-50.

11. Kinsella, E.M., Mayne, E.O.J., (1966), Ionic conduction in polymer film. 3rd International congress on metallic corrosion, Moscow, 117-120.

12. Kamal, M.R., Saxon, R., (1967), Analysis and predictability of weathering. Applied Polymer Symposium, 4, 1-28.

13. Obal, W.D., (2000), Semiconductor. Fabtech 11th Ed., 131-136.

14. ASTM F739, (2001), Annual book of ASTM standards, 11 (03) (ASTM, Baltimore).

15. ASTM F903, (2001), Annual book of ASTM standards, 11 (03) (ASTM, Baltimore). 